\title{
Preparation of anti-bacterial cellulose fiber via electrospinning and crosslinking with $\beta$-cyclodextrin
}

\author{
Youngwoong Kang ${ }^{1}$, Yong Keun $\mathrm{Choi}^{3}$, Hyoung Joo Kim ${ }^{3}$, Younghan Song ${ }^{2}$ and Hyungsup Kim²*
}

*Correspondence:

iconclast@konkuk.ac.kr

${ }^{2}$ Department

of Organic and Nano

System Engineering,

Konkuk University, 120

Neungdong-ro, Gwangjin-gu,

Seoul 143-701, Republic

of Korea

Full list of author information

is available at the end of the article

\begin{abstract}
In the study, we successfully produced electrospun cellulose fibers crosslinked with $\beta$-CD. For electrospinning, cellulose was dissolve in 1-ethyl-3-methylimidazolium acetate and DMF was added to the prepared solution for better spinnability. The prepared cellulose fiber was immersed in the solution containing $\beta$-CD, crosslinking agent and sodium hypophosphite. In order to understand the effect of a crosslinking agent, two different types of the agents, BTCA (1,2,3,4-butanetetracarboxylic acid) and citric acid with various concentrations were used for cross-linking. The crosslinking degree was increased with the concentration of the crosslinking agents, for the both agents. The cross-linked web changed into membrane like morphology when the concentration of the cross-linking agent was higher than $5 \mathrm{wt} \%$. The concentration of crosslinking agent also gave influence on the crystallinity, the thermal property and the antibacterial activity of fibers. Due to the cross-linking the crystallinity was decreased. The crosslinked fiber showed selective bacterial behavior according to the bacterial strain and the cross-linking agent.
\end{abstract}

Keywords: Cellulose, Cyclodextrin, Electrospinning, lonic liquid, Co-solvent, Crosslinking

\section{Introduction}

Cyclodextrins (CDs) are doughnut-shaped oligosaccharides consisting of $\alpha(1,4)$-linked glucopyranose. Due to their amphiphilicity, CDs are expected to be applied in many areas such as drug delivery, chromatography, selective removal and solubility enhancement (Araki and Ito 2007; Del Valle 2004; Giuffrida et al. 2006; Hedges 1998; Naidoo et al. 2004; Szejtli 1998).

Cyclodextrins are found as many different forms depending on the number of glucose units. Three of the most important cyclodextrins are $\alpha-, \beta-$, and $\gamma$-CDs which are consisting of 6, 7 and 8 glucose units, respectively. Among them, $\beta-C D$ takes more attentions due to its relatively simple manufacturing process and high productivity (Del Valle 2004). As a carrier of antibacterial agent or drug, $\beta$-CD is one of the most effective materials. Sun et al. (2011) studied the in vitro antibacterial activity of cyclodextrin-drug complexes using $\beta$-cyclodextrin and 2-hydroxypropyl $\beta$-cyclodextrin. The complexation of the antibacterial drug with the CDs improved the antibacterial activity by steady-state

(C) 2015 Kang et al. This article is distributed under the terms of the Creative Commons Attribution 4.0 International License (http:// creativecommons.org/licenses/by/4.0/), which permits unrestricted use, distribution, and reproduction in any medium, provided you give appropriate credit to the original author(s) and the source, provide a link to the Creative Commons license, and indicate if changes were made. 
release of the drug. While the cyclodextrin-drug complexes were still studied by many researchers, the antibacterial activity of pure $\beta-C D$ itself has not been intensively investigated.

Recently, many researchers are interested in $\beta$-CD nanofiber because it can dramatically improve desirable properties by increase of the specific surface area (Fong et al. 1999; Huang et al. 2003; Li and Xia 2004; Li et al. 2005; Schiffman and Schauer 2008; Zhang et al. 2005). However, the molecular interactions of small molecules including $\beta-C D$ are not strong enough to prevent stream breakage in uniaxial deformation during spinning. In order to produce nanofiber, $\beta$-CD needs to be mixed with carrier polymers such as PEO (Uyar and Besenbacher 2009), PAN (Wang et al. 2012), PMMA (Uyar et al. 2010), PVA (Zhang et al. 2011) etc. The mixed solutions were successfully electrospun into sub-micron size fibers. However, this method has several drawbacks with respect to processing and performance. The first drawback is difficult to select an optimal solvent which can dissolve both polymer and $\beta-C D$ with proper concentration. The polymer also needs to be thermodynamically comparable with $\beta-C D$ in order to guarantee good spinnability. Plus, it is difficult to control the location of $\beta-C D$ on the fiber surface for better functionality.

Recent researches showed the possibility that small molecules such as phospholipid and gemini surfactant could be electrospun into nanofiber when the molecules have entangled micelle networking (Cashion et al. 2009; McKee et al. 2006). The strong hydrogen boding induced by many $-\mathrm{OH}$ groups in $\beta$-CD make the molecules possible to form networking structure similarly to phospholipid and gemini surfactant. However, comparing to $\alpha$ - and $\gamma$-CDs, $\beta$-CD has very poor solubility in conventional solvents due to the local water held in the cavity and around the molecules (Naidoo et al. 2004). The local water makes $\beta$-CD rigid macro-cyclic compound, which is not easily accommodated into conventional solvent system (Naidoo et al. 2004). This poor solubility of $\beta$-CD did not allow the direct dissolution for electrospinning. To improve the solubility, the external hydrophilic groups are chemically modified into hydrophobic groups such as hydroxypropyl and methyl groups (Celebioglu and Uyar 2010, 2011, 2012; Manasco et al. 2012). The modified CD showed better solubility and successfully electrospun into nanofiber. Recently our research group reported direct dissolution of unmodified $\beta-C D$ using ionic liquid and successful electrospinning of the prepared solution (Ahn et al. 2013). However, the electrospun $\beta$-CD was mechanically weak and brittle for further applications.

To overcome the weaknesses of the two methods (spinning with carrier polymer and direct spinning), we cross-linked $\beta$-CD on the surface of electrospun cellulose fiber. The cross-linked fiber is mechanically acceptable and has selective anti-bacterial properties, which would be beneficial for biomedical applications due to its biocompatibility as well as biodegradability.

\section{Methods}

\section{Materials}

$\beta$-CD (Mw 1,134.99, purity $>95 \%)$ was purchased from Tokyo Chemical Industry Company (Japan). Cellulose (DP 1100) for the study was obtained as powder from Hyosung Co. (Korea). Ionic liquid (1-ethyl-3-methylimidazolium acetate) and dimethylformamide 
(DMF) were purchased from BASF (Germany) and Daejung Chemicals \& Metals Co. (Korea), respectively. 1,2,3,4-butanetetracarboxylic acid (BTCA, 98\%), citric acid (>99.5\%) and sodium hypophosphite (>98\%) were purchased from Sigma-Aldrich. All chemicals and materials were used without further purification.

\section{Electrospinning}

The solutions for electrospinning were prepared by dissolving cellulose in the ionic liquid. The concentration of cellulose was kept as $12 \mathrm{wt} \%$. DMF was added to the solution to improve the spinnability (Ahn et al. 2012). The ratio of ionic liquid to DMF was fixed at 5:5.

The prepared solutions were electrospun using a syringe type electrospinning apparatus on to a rotating wired cylinder. The tip was a $20 \mathrm{G}$ stainless steel needle having $0.60 \mathrm{~mm}$ inner diameter. In the all experiments, the applied voltage and TCD (tip-docollector distance) were $30 \mathrm{kV}$ and $15 \mathrm{~cm}$, respectively. The air pressure was fixed as $0.1 \mathrm{MPa}$.

The electrospun cellulose was immersed in ethanol at $4^{\circ} \mathrm{C}$ for $2 \mathrm{~h}$ to remove ionic liquid and DMF. The coagulated fiber was dried at ambient condition for a day.

\section{Crosslinking}

1,2,3,4-butanetetracarboxylic acid or citric acid was used for cross-linking. The prepared cellulose fiber was immersed in the solution containing $\beta-C D$, crosslinking agent and sodium hypophosphite. In order to understand the effect of the crosslinking agent on the fiber properties, experiments were carried out under the conditions shown in Table 1. All impregnated samples were pre-dried at $90^{\circ} \mathrm{C}$ for $20 \mathrm{~min}$ and then cross-linked at $180^{\circ} \mathrm{C}$ for $10 \mathrm{~min}$. The cross-linked fibers were rinsed with distilled water and dried at room temperature.

\section{Characterizations}

The morphologies of the electrospun fibers were observed using scanning electron microscopy (FE-SEM S-4700, Hitachi, Japan). The cross-linking in the fibers were examined using FT-IR (FT-IR, Nicolet 6700, USA) with ATR Acc. (window ZnSe/diamond). The numbers of scanning, resolution and wavenumber range were 32, 8 and $1,200-1,800 \mathrm{~cm}^{-1}$, respectively. X-ray diffraction (XRD) patterns were obtained using High Resolution XRD (Ultima IV, Rigaku, Japan) to investigate the micro-structure. The basis for the equation of the crystallinity degree was calculated using a computer program (ProFit V1.0, Philips Electronics N.V, Netherlands). The thermal properties were

Table 1 Solution preparation conditions

\begin{tabular}{llll}
\hline CD (wt\%) & BTCA (wt\%) & CA (wt\%) & Catalyst (wt\%) \\
\hline 5 & 2 & - & 1.5 \\
5 & 5 & - & 1.5 \\
5 & 8 & - & 1.5 \\
5 & - & 2 & 1.5 \\
5 & - & 5 & 1.5 \\
5 & - & 8 & 1.5 \\
\hline
\end{tabular}


evaluated by TGA (Q500, TA Instruments, USA). The TGA curves were obtained under a nitrogen atmosphere at a heating rate of $10^{\circ} \mathrm{C} / \mathrm{min}$ until $600^{\circ} \mathrm{C}$.

\section{Antibacterial susceptibility test}

The bacterial strains used in this study, Staphylococcus aureus KCTC 1621 (Gram positive) and Escherichia coli KCTC 1682 (Gram negative) were obtained from the Korean Collection for Type Culture (KCTC; Daejeon, Korea). After the pre-cultured bacteria cell for $18 \mathrm{~h}$ was adjusted according to $0.5 \mathrm{McF}$ arland standards, the bacteria cell was spread onto Nutrient broth agar in a Petridish (Cauwelier et al. 2004; Pervin et al. 2012). The cross-linked cellulose web was cut into $10 \mathrm{~mm}$ squares and was located on the petridish. The petridish was incubated at $37^{\circ} \mathrm{C}$ for $24 \mathrm{~h}$ and the bacterial activity was observed.

\section{Results and discussion}

\section{FT-IR spectroscopy}

Figure 1 shows the FT-IR spectra of the cellulose fibers before and after $\beta$-CD crosslinking. The cross-linked fiber showed a characteristic peak at $1,727 \mathrm{~cm}^{-1}$, which is corresponding to $\mathrm{C}=\mathrm{O}$ stretching vibration mode of an ester bond (Medronho et al. 2013; Reddy and Yang 2010; Yang et al. 2010). It suggests that the carboxylic acid of the agent was successfully cross-linked the $\beta$-CD with the cellulose nanofiber by ester bonding (Medronho et al. 2013).

The characteristic peak $\left(1,727 \mathrm{~cm}^{-1}\right)$ was increased as the concentration of the crosslinking agent increased. For the case of citric acid, the peak was slightly increased with the concentration of citric acid. For the case of BTCA, however, the peak was considerably increased with the acid concentration and was larger comparing to the citric acid case at higher concentration. This indicates that BTCA is more effective for cross-linking than citric acid, which is coincident to the result of previous studies (Chung et al. 1998; El-Tahlawy et al. 2005).

\section{Morphology}

Figure 2 shows the SEM images of the pristine and the cross-linked cellulose fibers. When the concentration of cross-linking agent was low, the morphologies of the

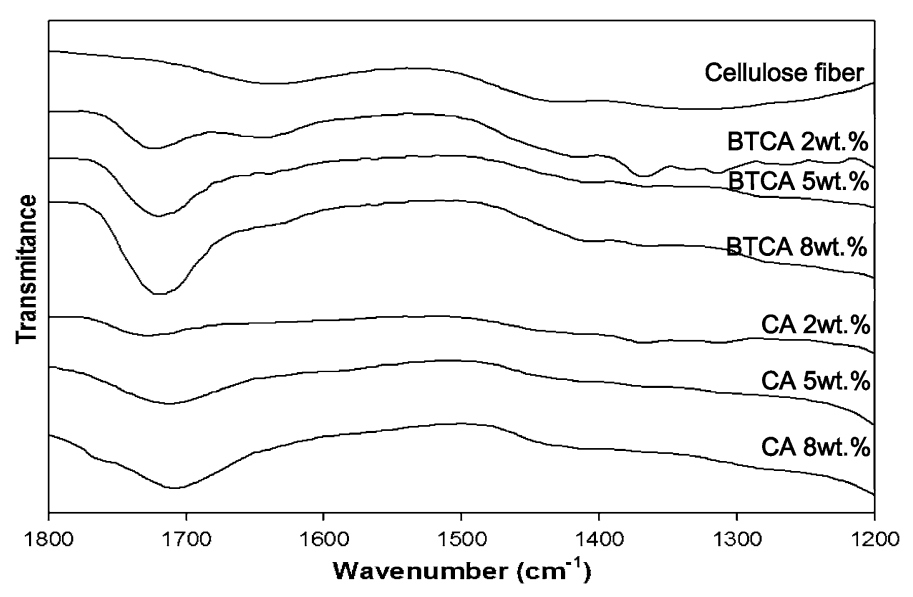

Figure 1 FT-IR spectra of electrospun and crosslinked cellulose fibers. 

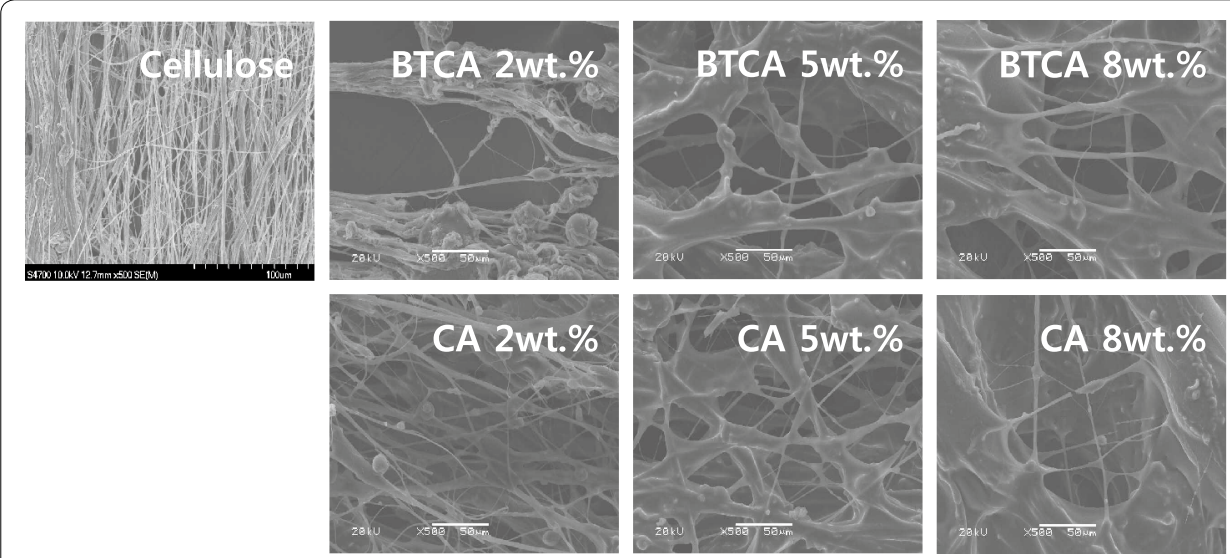

Figure 2 SEM images of electrospun and crosslinked cellulose fibers.

cross-linked cellulose fibers were similar to the pristine cellulose fiber regardless of the cross-linking agent types. As the concentration of the cross-linking agent increased over $5 \mathrm{wt} \%$, the membrane-like shape started to appear. The further increase of the agent concentration resulted in film-like web morphology. This morphology change was similarly was observed in other researches (Chen et al. 2012; Liu et al. 2007).

\section{Microstructure}

Figure 3 shows the XRD spectra of the pristine and the cross-linked cellulose fibers. The degree of crystallinity was calculated from the following equation and summarized in Table 2.

$$
\text { Degree of Crystallinity }(\%)=\frac{\text { Intensity of Crystalline scattering }}{\text { Total Scattering Intensity }} \times 100
$$

As shown in Table 2, the crystallinity was decreased as the concentration of the crosslinking agent increased. When cellulose was cross-linked with $\beta-C D$, the intermolecular

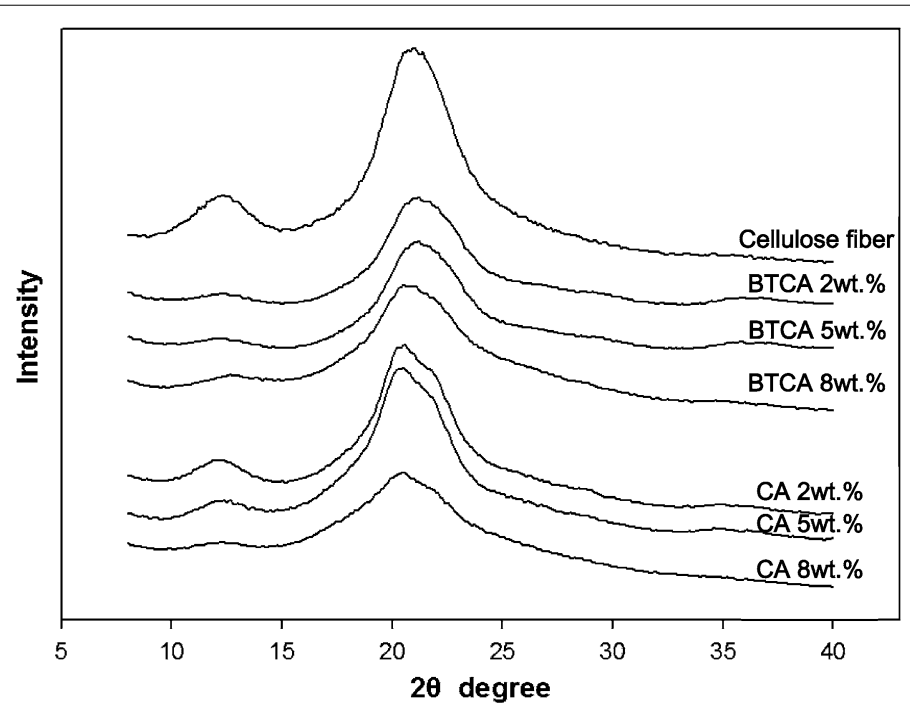

Figure 3 XRD spectra of electrospun and crosslinked cellulose fibers. 
Table 2 Degree of crystallinity

\begin{tabular}{ll}
\hline Sample & Degree of crystallinity (\%) \\
\hline Cellulose & 75 \\
BTCA 2 wt\% & 55.7 \\
BTCA 5 wt\% & 37.5 \\
BTCA 8 wt\% & 36.5 \\
CA 2 wt $\%$ & 56.2 \\
CA 5 wt $\%$ & 44.0 \\
CA 8 wt $\%$ & 29.9 \\
\hline
\end{tabular}

hydrogen bonding became weaker because of the substitution of hydroxyl group with $\beta-C D$. At the same time, the cellulose chain-to-chain distance increased due to the attached molecules. As a result, the more cross-linked cellulose showed lower crystallinity due to the higher concentration of the crosslinking agent.

\section{Thermal property}

Figures 4 and 5 show the TGA and DTG curves of the pristine and the cross-linked cellulose fibers. The types of the cross-linking agents did not show critical influence on the thermal stability of the resulted fibers. The cross-linked fibers decomposed in lower temperature than the pristine cellulose fiber. The poor thermal stability might be caused by molecular degradation during the cross-linking process. Although we did not provide the experimental results, it is well known the acidic crosslinking agent could cause the acid hydrolysis of cellulose and in turn resulted in low molecular weight. The crystallinity might also influence on the thermal stability of the resulted fibers. The fiber with lower crystallinity due to higher crosslinking showed lower thermal stability. As explained in other literature (Ahn et al. 2013), low crystalline polymers are thermally unstable due to low chain-to-chain interaction.

\section{Antibacterial susceptibility}

The antibacterial activities of the pristine and the cross-linked fibers were investigated by comparing of the $\beta$-CD fiber prepared in the previous study (Ahn et al. 2013). The $\beta$-CD fibers and cross-linked cellulose fibers with citric acid showed antibacterial activities on the Gram positive bacteria, Staphylococcus aureus as shown in Figure 6. The $\beta$-CD fibers showed better antibacterial activity comparing to the other fibers. The doughnut-shaped chemical structure and many hydroxyl groups of $\beta-\mathrm{CD}$ made stronger bonding with bacteria than cellulose.

As shown in the figure, the antibacterial effect toward Gram positive S. aureus was observed with the increase of citric acid concentration. However, when the cross-linked cellulose fibers with BTCA were applied, no effect has been noticed on the tested bacterial strain. Especially, in the case of Gram negative bacteria, E. coli, no antibacterial activity effect was observed on most cellulose fibers. Although it is still not known why the this difference in the antibacterial susceptibility was originated, the result may be due to the difference in release rate of toxic materials (i.e. cross-linking agents) form the fabric, differences of membrane structure of bacterial strains, or susceptibility against 

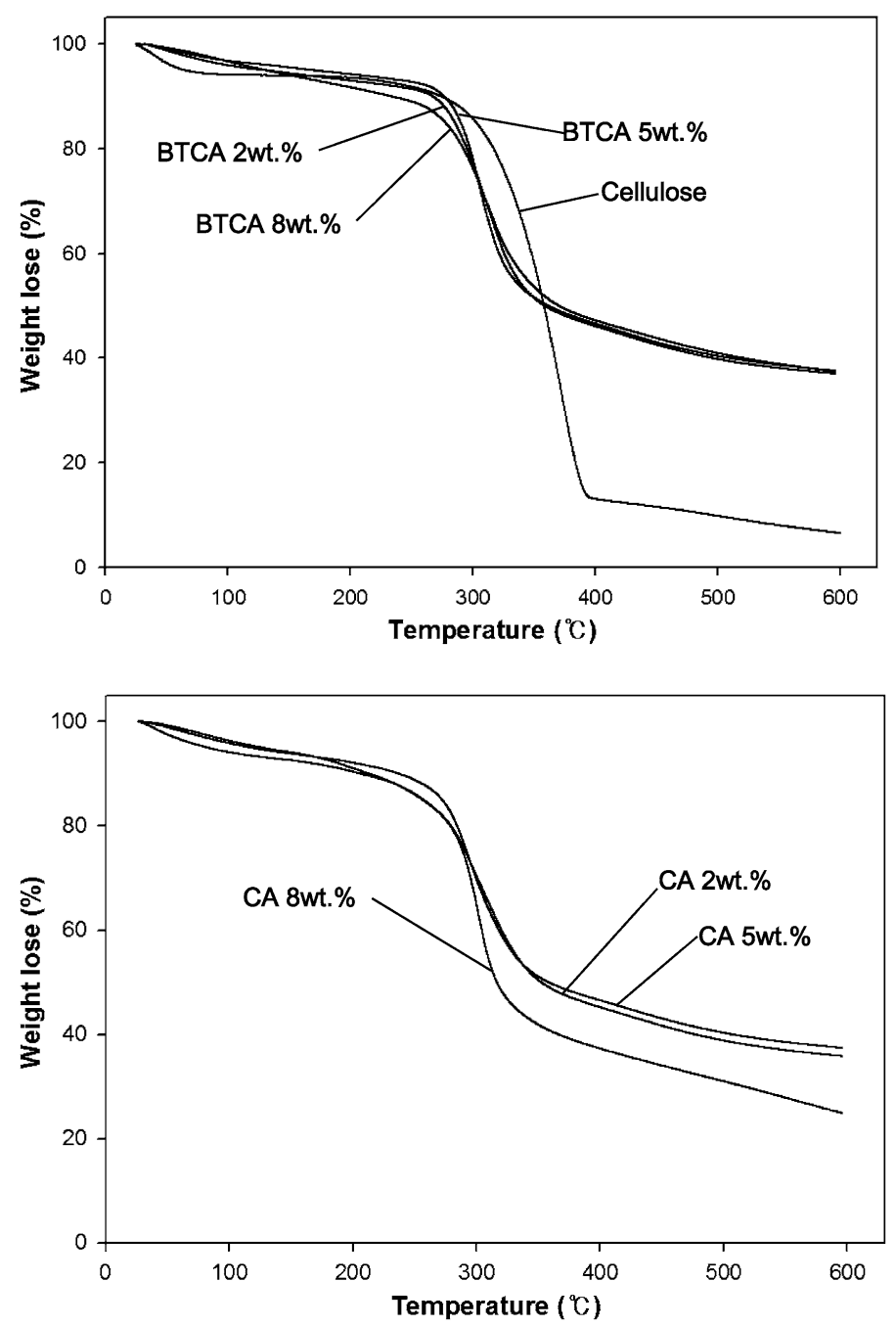

Figure 4 TGA curves of electrospun and crosslinked cellulose fibers.

antibacterial materials released from the fabric (Gupta 2011; Kim et al. 1997; Orhan et al. 2009).

\section{Conclusion}

$\beta$-CD was successfully cross-linked with electrospun cellulose fibers using BTCA and citric acid. As the concentration of crosslinking agent increased, more $\beta$-CD was cross-linked with the cellulose fiber. It resulted in lower crystallinity due to $\beta$-CD cross-linked to cellulose and smaller secondary bonding between the polymer chains. The cross-linked fibers show selective antibacterial effect according to type of cross-linking agent and bacteria. 

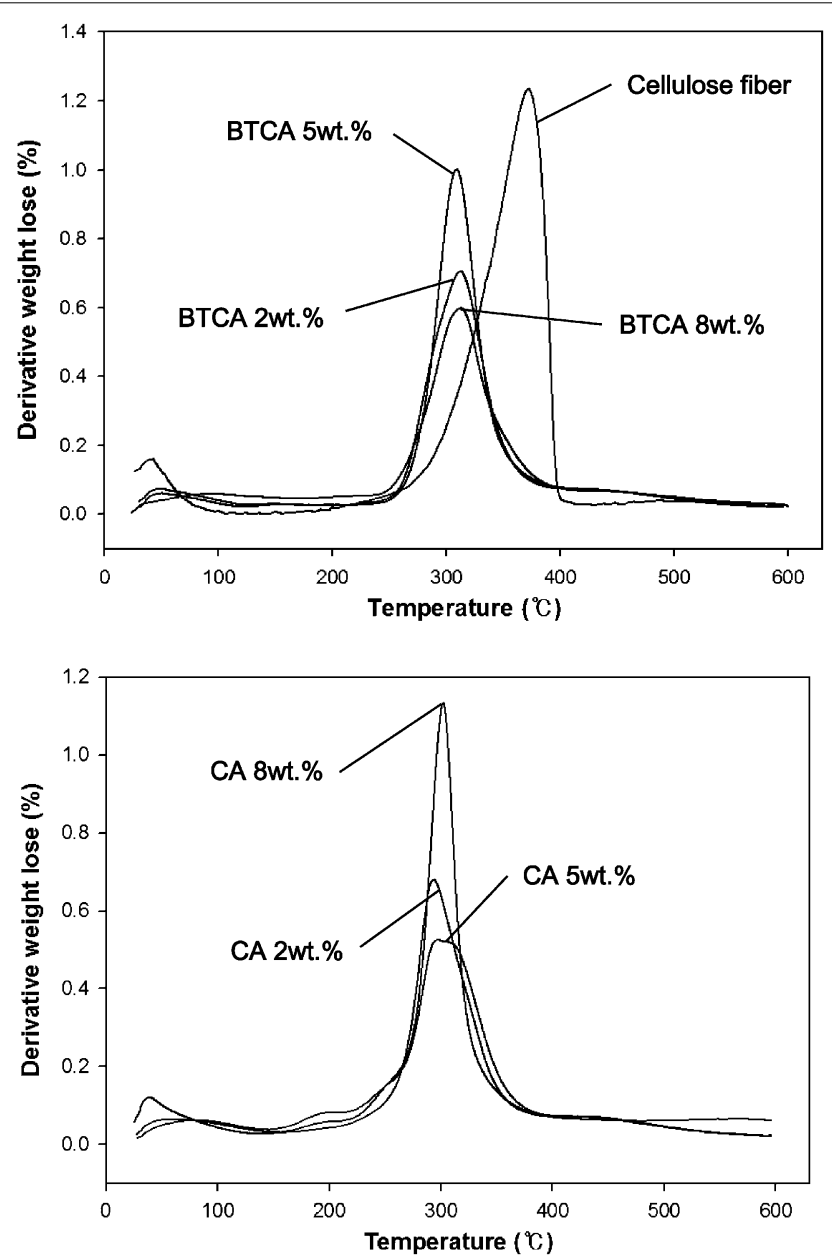

Figure 5 DTG curves of electrospun and crosslinked cellulose fibers.

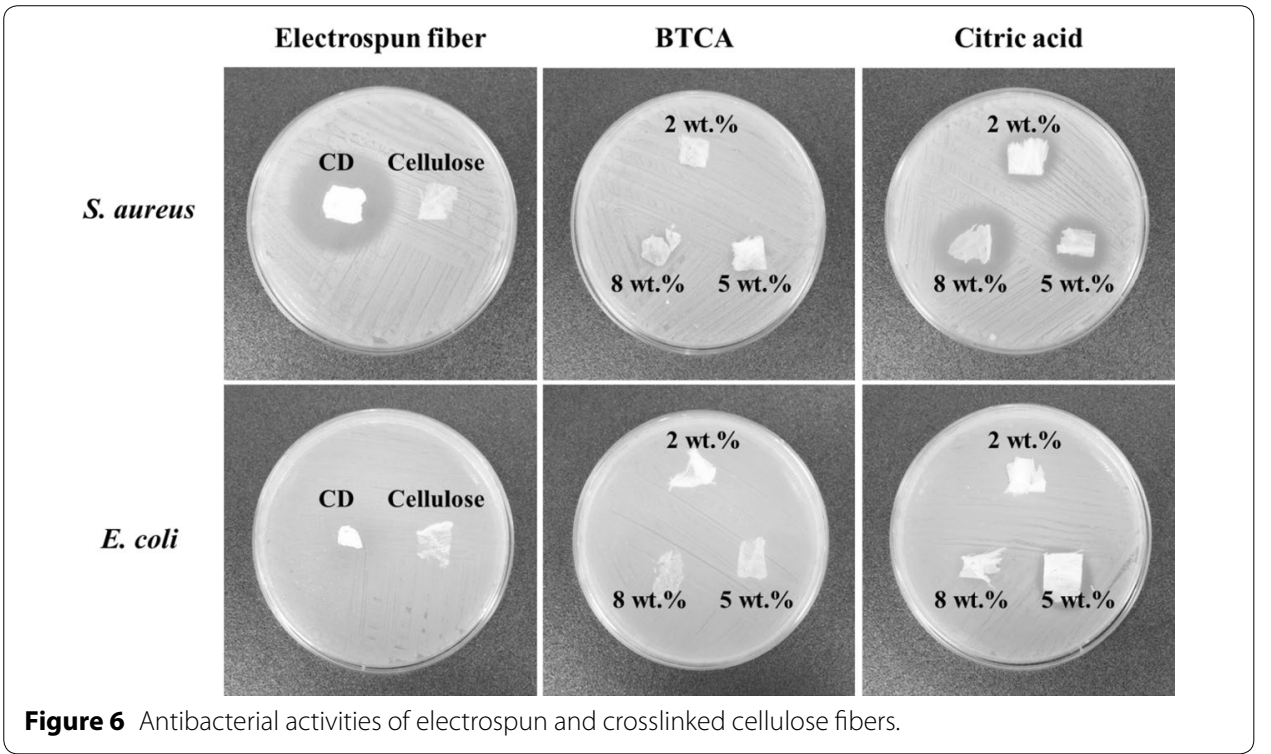




\section{Authors' contribution}

The authors in the article contributed as follows; Mr. WK electrospun cellulose nanofibers and cross-linked CD with the fiber and Mr. YS characterize the CD attached cellulose nanofibers. Drs. YC and HJK evaluated the antibacterial properties. $H K$, myself is a corresponding author who designed and controlled the whole research and prepared the manuscript. All authors agree to the publication of the article on Fashion and Textile Engineering. All authors read and approved the final manuscript.

\section{Author details}

${ }_{1}^{1}$ Department of Textile Engineering, Konkuk University, 120 Neungdong-ro, Gwangjin-gu, Seoul 143-701, Republic of Korea. ${ }^{2}$ Department of Organic and Nano System Engineering, Konkuk University, 120 Neungdong-ro, Gwangjin-gu, Seoul 143-701, Republic of Korea. ${ }^{3}$ Department of Microbial Engineering, Konkuk University, 120 Neungdong-ro, Gwangjin-gu, Seoul 143-701, Republic of Korea.

\section{Acknowledgements}

This work was supported by the Industrial strategic technology development program funded by the Ministry of Trade, Industry \& Energy (MI, Korea) (10041237). This research was supported by Basic Science Research Program through the National Research Foundation of Korea (NRF) funded by the Ministry of Science, ICT and Future Planning (2012R1A1A2008620).

\section{Compliance with ethical guidelines}

\section{Competing interests}

The authors declare that they have no competing interests.

Received: 20 November 2014 Accepted: 12 June 2015

Published online: 14 July 2015

\section{References}

Ahn, Y., Hu, D.-H., Hong, J. H., Lee, S. H., Kim, H. J., \& Kim, H. (2012). Effect of co-solvent on the spinnability and properties of electrospun cellulose nanofiber. Carbohydrate Polymers, 89(2), 340-345.

Ahn, Y., Kang, Y., Ku, M., Yang, Y.-H., Jung, S., \& Kim, H. (2013). Preparation of $\beta$-cyclodextrin fiber using electrospinning. RSC Advances, 3(35), 14983-14987.

Araki, J., \& Ito, K. (2007). Recent advances in the preparation of cyclodextrin-based polyrotaxanes and their applications to soft materials. Soft Matter, 3(12), 1456-1473.

Cashion, M. P., Li, X., Geng, Y., Hunley, M. T., \& Long, T. E. (2009). Gemini surfactant electrospun membranes. Langmuir, 26(2), 678-683.

Cauwelier, B., Gordts, B., Descheemaecker, P., \& Van Landuyt, H. (2004). Evaluation of a disk diffusion method with cefoxitin $(30 \mu \mathrm{g})$ for detection of methicillin-resistant Staphylococcus aureus. European Journal of Clinical Microbiology and Infectious Diseases, 23(5), 389-392.

Celebioglu, A., \& Uyar, T. (2010). Cyclodextrin nanofibers by electrospinning. Chemical Communications, 46(37), 6903-6905.

Celebioglu, A., \& Uyar, T. (2011). Electrospinning of polymer-free nanofibers from cyclodextrin inclusion complexes. Langmuir, 27(10), 6218-6226.

Celebioglu, A., \& Uyar, T. (2012). Electrospinning of nanofibers from non-polymeric systems: Polymer-free nanofibers from cyclodextrin derivatives. Nanoscale, 4(2), 621-631.

Chen, Z., Wang, L., \& Jiang, H. (2012). The effect of procyanidine crosslinking on the properties of the electrospun gelatin membranes. Biofabrication, 4(3), 035007.

Chung, Y.-S., Lee, K.-K., \& Kim, J.-W. (1998). Durable press and antimicrobial finishing of cotton fabrics with a citric acid and chitosan treatment. Textile Research Journal, 68(10), 772-775.

Del Valle, E. M. (2004). Cyclodextrins and their uses: A review. Process Biochemistry, 39(9), 1033-1046.

El-Tahlawy, K. F., El-Bendary, M. A., Elhendawy, A. G., \& Hudson, S. M. (2005). The antimicrobial activity of cotton fabrics treated with different crosslinking agents and chitosan. Carbohydrate Polymers, 60(4), 421-430.

Fong, H., Chun, I., \& Reneker, D. (1999). Beaded nanofibers formed during electrospinning. Polymer, 40(16), $4585-4592$.

Giuffrida, S., Ventimiglia, G., Petralia, S., Conoci, S., \& Sortino, S. (2006). Facile light-triggered one-step synthesis of small and stable platinum nanoparticles in an aqueous medium from a $\beta$-cyclodextrin host-guest inclusion complex. Inorganic Chemistry, 45(2), 508-510.

Gupta, R. S. (2011). Origin of diderm (Gram-negative) bacteria: antibiotic selection pressure rather than endosymbiosis likely led to the evolution of bacterial cells with two membranes. Antonie van Leeuwenhoek, 100(2), 171-182.

Hedges, A. R. (1998). Industrial applications of cyclodextrins. Chemical Reviews, 98(5), 2035-2044.

Huang, Z.-M., Zhang, Y.-Z., Kotaki, M., \& Ramakrishna, S. (2003). A review on polymer nanofibers by electrospinning and their applications in nanocomposites. Composites science and technology, 63(15), 2223-2253.

Kim, C. H., Kim, S. Y., \& Choi, K. S. (1997). Synthesis and antibacterial activity of water-soluble chitin derivatives. Polymers for Advanced Technologies, 8(5), 319-325.

Li, M., Mondrinos, M. J., Gandhi, M. R., Ko, F. K., Weiss, A. S., \& Lelkes, P. I. (2005). Electrospun protein fibers as matrices for tissue engineering. Biomaterials, 26(30), 5999-6008.

Li, D., \& Xia, Y. (2004). Electrospinning of nanofibers: Reinventing the wheel? Advanced Materials, 16(14), 1151-1170.

Liu, H., Zhen, M., \& Wu, R. (2007). lonic-strength-and pH-responsive poly [acrylamide-co-(maleic acid)] hydrogel nanofibers. Macromolecular Chemistry and Physics, 208(8), 874-880. 
Manasco, J. L., Saquing, C. D., Tang, C., \& Khan, S. A. (2012). Cyclodextrin fibers via polymer-free electrospinning. RSC Advances, 2(9), 3778-3784.

McKee, M. G., Layman, J. M., Cashion, M. P., \& Long, T. E. (2006). Phospholipid nonwoven electrospun membranes. Science, 311(5759), 353-355.

Medronho, B., Andrade, R., Vivod, V., Ostlund, A., Miguel, M., Lindman, B., et al. (2013). Cyclodextrin-grafted cellulose: Physico-chemical characterization. Carbohydrate Polymers, 93(1), 324-330.

Naidoo, K. J., Chen, J. Y.-J., Jansson, J. L., Widmalm, G., \& Maliniak, A. (2004). Molecular properties related to the anomalous solubility of $\beta$-cyclodextrin. The Journal of Physical Chemistry B, 108(14), 4236-4238.

Orhan, M., Kut, D., \& Gunesoglu, C. (2009). Improving the antibacterial activity of cotton fabrics finished with triclosan by the use of 1, 2, 3, 4-butanetetracarboxylic acid and citric acid. Journal of Applied Polymer Science, 111(3), 1344-1352.

Pervin, R., Sabrin, F., Billah, M. M., Islam, K. D., Elmezughi, J., \& Shilpi, J. A. (2012). Antibacterial and cytotoxic activity of Meyna spinosa Roxb. Stem. Turkish Journal of Pharmaceutical Sciences, 9(2), 225-230.

Reddy, N., \& Yang, Y. (2010). Citric acid cross-linking of starch films. Food Chemistry, 118(3), 702-711.

Schiffman, J. D., \& Schauer, C. L. (2008). A review: Electrospinning of biopolymer nanofibers and their applications. Polymer Reviews, 48(2), 317-352.

Sun, H.-K., Seshadri, M., Lingard, S., Monaghan, W., Faoagali, J., Chan, E., et al. (2011). Antibacterial activity of $\beta$-cyclodextrin and 2-hydroxypropyl- $\beta$-cyclodextrin trimethoprim complexes. American Journal of Microbiology, 2(1), 1.

Szejtli, J. (1998). Introduction and general overview of cyclodextrin chemistry. Chemical Reviews, 98(5), 1743-1754.

Uyar, T., \& Besenbacher, F. (2009). Electrospinning of cyclodextrin functionalized polyethylene oxide (PEO) nanofibers. European Polymer Journal, 45(4), 1032-1037.

Uyar, T., Havelund, R., Nur, Y., Balan, A., Hacaloglu, J., Toppare, L., et al. (2010). Cyclodextrin functionalized poly (methyl methacrylate)(PMMA) electrospun nanofibers for organic vapors waste treatment. Journal of Membrane Science, $365(1), 409-417$

Wang, S., Bai, J., Li, C., \& Zhang, J. (2012). Functionalization of electrospun $\beta$-cyclodextrin/polyacrylonitrile (PAN) with silver nanoparticles: Broad-spectrum antibacterial property. Applied Surface Science, 261, 499-503.

Yang, C. Q., Chen, D., Guan, J., \& He, Q. (2010). Cross-linking cotton cellulose by the combination of maleic acid and sodium hypophosphite. 1. Fabric wrinkle resistance. Industrial and Engineering Chemistry Research, 49(18), 8325-8332.

Zhang, W., Chen, M., \& Diao, G. (2011). Electrospinning $\beta$-cyclodextrin/poly (vinyl alcohol) nanofibrous membrane for molecular capture. Carbohydrate Polymers, 86(3), 1410-1416.

Zhang, Y., Ouyang, H., Lim, C. T., Ramakrishna, S., \& Huang, Z. M. (2005). Electrospinning of gelatin fibers and gelatin/PCL composite fibrous scaffolds. Journal of Biomedical Materials Research. Part B, Applied Biomaterials, 72(1), 156-165.

\section{Submit your manuscript to a SpringerOpen ${ }^{\circ}$ journal and benefit from:}

- Convenient online submission

- Rigorous peer review

- Immediate publication on acceptance

- Open access: articles freely available online

- High visibility within the field

- Retaining the copyright to your article

Submit your next manuscript at $\mathbf{s p r i n g e r o p e n . c o m ~}$ 